\title{
COVID-19 Impairs Immune Response to Candida albicans
}

\author{
Dominique Moser, Katharina Biere, Bing Han, Marion Hoerl, Gustav Schelling, \\ Alexander Choukér ${ }^{*}$ and Tobias Woehrle
}

Department of Anesthesiology, LMU Hospital, Ludwig-Maximilians-University, Munich, Germany

Infection with SARS-CoV-2 can lead to Coronavirus disease-2019 (COVID-19) and result in severe acute respiratory distress syndrome (ARDS). Recent reports indicate an increased rate of fungal coinfections during COVID-19. With incomplete understanding of the pathogenesis and without any causative therapy available, secondary infections may be detrimental to the prognosis. We monitored 11 COVID-19 patients with ARDS for their immune phenotype, plasma cytokines, and clinical parameters on the day of ICU admission and on day 4 and day 7 of their ICU stay. Whole blood stimulation assays with lipopolysaccharide (LPS), heat-killed Listeria monocytogenes (HKLM), Aspergillus fumigatus, and Candida albicans were used to mimic secondary infections, and

\section{OPEN ACCESS}

Edited by:

Jean-Marc Cavaillon, Institut Pasteur, France

Reviewed by: Vera Lucia Garcia Calich, University of São Paulo, Brazil Chien-Hsiung Pan, National Health Research Institutes,

Taiwan

*Correspondence: Alexander Choukér achouker@/mu.de

Specialty section: This article was submitted to Inflammation, a section of the journal Frontiers in Immunology

Received: 11 December 2020 Accepted: 20 January 2021 Published: 26 February 2021

Citation: Moser D, Biere K, Han B, Hoerl M, Schelling G, Choukér $A$ and Woehrle T (2021) COVID-19 Impairs Immune Response to Candida albicans. Front. Immunol. 12:640644. doi: 10.3389/fimmu.2021.640644 changes in immune phenotype and cytokine release were assessed. COVID-19 patients displayed an immune phenotype characterized by increased HLA-DR ${ }^{+} \mathrm{CD} 38^{+}$ and $\mathrm{PD}-1^{+} \mathrm{CD} 4^{+}$and $\mathrm{CD} 8^{+} \mathrm{T}$ cells, and elevated $\mathrm{CD} 8^{+} \mathrm{CD} 244^{+}$lymphocytes, compared to healthy controls. Monocyte activation markers and cytokines IL-6, IL-8, TNF, IL-10, and sIL2R $\alpha$ were elevated, corresponding to monocyte activation syndrome, while IL-1 $\beta$ levels were low. LPS, HKLM and Aspergillus fumigatus antigen stimulation provoked an immune response that did not differ between COVID-19 patients and healthy controls, while COVID-19 patients showed an attenuated monocyte CD80 upregulation and abrogated release of IL-6, TNF, IL-1 $\alpha$, and IL-1 $1 \beta$ toward Candida albicans. This study adds further detail to the characterization of the immune response in critically ill COVID-19 patients and hints at an increased susceptibility for Candida albicans infection.

Keywords: second hit, lipopolysaccharide, Listeria monocytogenes, yeast, fungal, SARS-CoV-2, acute respiratory distress syndrome

\section{INTRODUCTION}

The novel coronavirus 2019-nCov, also named SARS-CoV-2, has rapidly spread around the globe since its discovery in Wuhan, China, in December 2019. Infection with SARS-CoV-2 can lead to Coronavirus disease 2019 (COVID-19), where respiratory symptoms may include cough, breathing difficulties, and in severe cases, result in acute respiratory distress syndrome (ARDS) $(1,2)$. COVID-19 induces a plethora

Abbreviations: AICD, activation-induced cell death; ARDS, acute respiratory distress syndrome; COV, COVID-19 cohort; COVID-19, coronavirus disease-2019; danger-associated molecular patterns; HC, healthy control cohort; HKLM, heat-killed Listeria monocytogenes; ICU, intensive care unit. 
of immunological reactions affecting the innate and adaptive immune responses, which are critical to the clinical course and outcome of patients. Severe COVID-19 can result in excessive cytokine release or immunosuppression, with substantial morbidity and mortality mostly in older patient populations (1, 3-5).

While in the beginning of the COVID-19 pandemic, superinfections have been rarely reported (6), reports about secondary fungal infections as complications of severe COVID-19 are on the rise. In COVID-19 patients with ARDS, COVID-19 associated pulmonary aspergillosis (6-8) and COVID-19 associated candidiasis (9-14) have been described to complicate the clinical course. Although the exact pathogenesis of these coinfections remains unclear, there are several immunological mechanisms that can facilitate the development of fungal diseases. SARS-CoV2 infection leads to the release of danger-associated molecular patterns. Consecutive activation of innate pattern recognition pathways may cause hyperinflammation during the antiviral immune response, leading to lung tissue damage and causing disruption of mucous membranes, thus contributing to an environment that allows for fungal infections (15-18). While most microbiological detection of Candida spp. as commensals does not have pathological relevance, transition into invasive candidiasis during critical illness has a reported lethality rate of up to $70 \%(19-21)$ and is considered a relevant complication in COVID-19 patients (15). Details regarding the susceptibility of these patients to Candida infection and characteristics of an impaired immune response have not been described yet.

In this study, 11 severe cases of COVID-19 with ARDS that required intubation and ICU treatment are characterized and compared to healthy controls. We detail the immune phenotype and cytokine release pattern of these patients on the day of admission, and on day 4 and day 7 of their ICU stay and present an ex vivo second hit model that reveals an impaired immune response against Candida albicans.

\section{MATERIALS AND METHODS}

\section{Study Subjects}

Patients with pneumonia resulting from confirmed SARS-CoV-2 infection were included in this study upon admittance to the ICU, when they required intubation and ventilation. Patients with a malignant disease or previous immunosuppressive therapy were excluded. All patients received treatment according to the standard COVID-19 treatment protocol as of April 2020, including azithromycin for 5 days, and hydroxychlorquine for 7 days. Arterial blood was drawn on the day of ICU admission (day 0 ; d0) and on day $4(\mathrm{~d} 4)$ and day 7 (d7) of the ICU stay. The patients' detailed clinical course was recorded electronically (QCare ICU, HIM GmbH, Bad Homburg, Germany). As controls, healthy volunteers were included.

\section{Ex Vivo Whole Blood Incubation Assay}

Lithium heparin whole blood $(300 \mu \mathrm{l})$ was diluted with an equal volume of RPMI 1640 (Sigma-Aldrich, Steinheim, Germany) and incubated with one of the following stimuli: Lipopolysaccharide (LPS; $10 \mu \mathrm{g} / \mathrm{ml}$; Sigma-Aldrich, Steinheim, Germany), heat-killed Listeria monocytogenes (HKLM; $10^{8}$ cells $/ \mathrm{ml}$; InvivoGen Europe, Toulouse, France), Aspergillus fumigatus (A. fumigatus; $10 \mu \mathrm{g} / \mathrm{ml}$; Raybiotech, Georgia, USA), Candida albicans lysate (C. albicans; 10 $\mu \mathrm{g} / \mathrm{ml}$; Allergopharma, Reinbeck, Germany), or vehicle only as negative control. Samples were incubated for $6 \mathrm{~h}$ at $37^{\circ} \mathrm{C}$. Following incubation, supernatants were collected and stored at $-80^{\circ} \mathrm{C}$ until cytokine measurement. The remaining sample was conserved with Transfix (Cytomark, Buckingham, UK) and stored at $4^{\circ} \mathrm{C}$ until flow cytometry analyses.

\section{Immune Phenotyping}

For T cells, $\mathrm{CD} 4^{+}$or $\mathrm{CD}^{+}$cells were stained for co-expression of CD69, HLA-DR, CD38, PD-1, CD28, CD244 and CD226. Central memory $\mathrm{T}$ cells were detected by additional staining for CD62L, CD45RA, and CD45RO. For monocytes, cells were stained for co-expression of CD14 and CD16, CD69, CD40, CD80, CD86, TLR2 or HLA-DR. Except for TLR2 (Cat. No. 130120-052, Miltenyi Biotec, Bergisch Gladbach, Germany), all antibodies were obtained from BD Biosciences (Cat. No. CD4: 555346, CD8: 557085, CD69-PE: 555531, HLA-DR: 559831, CD38: 345806, PD-1: 561273, CD28: 337181, CD244: 562350, CD226: 338314, CD62L: 555544, CD45RA: 550855, CD45RO: 560607, CD14: 345784, CD16: 338440, CD69-PerCp: 340548, CD40: 555589, CD80: 557227, CD86: 555665, Franklin Lakes, NJ, USA). Samples and antibodies were incubated for $20 \mathrm{~min}$ at room temperature, lysed for $10 \mathrm{~min}$ (BD FACS lysing solution, BD Biosciences Franklin Lakes, NJ, USA), washed, and analyzed by flow cytometry (Guava ${ }^{\circledR}$ easyCyte ${ }^{\mathrm{TM}}$ 8HT Flow Cytometer, Merck Millipore, Billerica, MA, USA). For each measurement, 10,000 events were recorded. Data analysis was performed with InCyte Software for Guava ${ }^{\circledR}$ easyCyte HT Systems (Merck Millipore, Billerica, MA, USA).

\section{Cytokine Measurements}

Cytokine concentrations in plasma samples and ex vivo incubation assay supernatants were quantified using the MAGPIX Multiplexing System (Luminex, Austin, TX, USA) and custom-made Multiplex assays for detection of IFN $\gamma$, IL-1 $\alpha$, IL-1 $\beta$, IL-2, IL-6, IL-8, IL-10, IL18 , TNF, and sIL2R $\alpha$, according to the manufacturer's instructions.

\section{Statistical Analyses}

Data analysis was performed with commercially available software (SigmaPlot 12.5, Systat, Erkrath, Germany; GraphPad Prism 8.1.1, San Diego, CA, USA). Unless otherwise stated, results are expressed as median (IQR). For comparison between two groups, two-tailed unpaired Student's $t$-test, Mann-Whitney- $U$ test or Fisher's exact test were used. Differences were considered significant at $P<.05$.

\section{Study Approval}

Informed consent was obtained from next of kins or carers of all patients and from healthy volunteers, respectively. This study was performed after obtaining the LMU Medical Faculty ethics 
committee approval (\#20-271 and \#19-778) and conducted in agreement with the ethical norms and standards of the Declaration of Helsinki (22).

\section{RESULTS}

\section{Study Population}

Between April and May 2020, 11 COVID-19 patients with ARDS were included in this study. The median age was 64 years, eight patients were male, and the median body mass index was 27.7 $\mathrm{kg} / \mathrm{m}^{2}$. The median Horowitz index upon admission (day 0; $\mathrm{d} 0$ ) was 107 (d4: 182; d7: 199), indicating moderate ARDS (Table 1). Median duration for the requirement of ventilation was 15 days, with 23 days of ICU care and 34 days of hospitalization. In four out of 11 patients, blood sampling was discontinued before $\mathrm{d} 4$ due to extubation $(n=1)$, transfer to a different hospital $(n=1)$, or withdrawal of consent for further blood sampling for research purposes $(n=2)$. All patients were transferred to a rehabilitation hospital or into primary physician care, and no fatal outcome occurred during the evaluated time period.

On ICU admission, COVID-19 patients presented with an increased leukocyte count due to elevated neutrophils, but with diminished lymphocyte count and lymphocyte and monocyte fractions. Thrombocytes were elevated but within the reference range, while erythrocytes and hemoglobin were reduced below the reference range, respectively. Characteristics of critically ill COVID-19 patients (COV) and healthy controls (HC) are summarized in Table $\mathbf{1}$.

\section{Immune State During Critical COVID-19}

The activation state of $\mathrm{T}$ cells and monocytes was assessed in COV on the day of ICU admission $(\mathrm{d} 0, \mathrm{n}=11)$ and in $\mathrm{HC}(\mathrm{n}=9)$, respectively. Time dependent changes were monitored by repeated analyses on $\mathrm{d} 4(\mathrm{n}=7)$ and $\mathrm{d} 7(\mathrm{n}=7)$ of the patients' ICU stay.

\section{$\mathrm{CD}^{+}$and $\mathrm{CD}^{+}{ }^{+}$Cell Phenotype}

In $\mathrm{COV}$, we detected a pronounced activation of $\mathrm{CD}^{+}$and $\mathrm{CD}^{+} \mathrm{T}$ cells with significantly augmented proportions of $\mathrm{CD} 9^{+}, \mathrm{HLA}-\mathrm{DR}^{+} \mathrm{CD} 38^{+}$and $\mathrm{PD}-1^{+}$cells (Figures 1A-C, EG). In addition, $\mathrm{CD}^{+}$but not $\mathrm{CD} 4^{+} \mathrm{T}$ cells showed a reduced surface expression of CD28 (Figures 1D, H), high levels of the cytotoxic cell marker molecule CD244, and increased CD226 expression (Figures 1I, J). The percentage of $\mathrm{CD}^{+} \mathrm{CD} 62 \mathrm{~L}^{+}$ $\mathrm{CD} 45 \mathrm{R}^{+} \mathrm{CD}^{2} 5 \mathrm{RA}^{-}$central memory $\mathrm{T}$ cells showed a pronounced reduction in $\mathrm{COV}$ compared to $\mathrm{HC}$ (Figure 1K), while $\mathrm{CD}^{+} \mathrm{CD} 6 \mathrm{~L}^{+} \mathrm{CD} 45 \mathrm{R} 0^{+} \mathrm{CD} 45 \mathrm{RA}^{-}$did not differ (not shown).

Over time $(\mathrm{d} 4, \mathrm{~d} 7)$, the percentage of $\mathrm{HLA}-\mathrm{DR}^{+} \mathrm{CD} 38^{+} \mathrm{CD} 4^{+}$ and $\mathrm{HLA}-\mathrm{DR}{ }^{+} \mathrm{CD} 38^{+} \mathrm{CD} 8^{+} \mathrm{T}$ cells increased, reaching statistical significance on $\mathrm{d} 7$, compared to $\mathrm{d} 0\left(\mathrm{CD} 4^{+} \mathrm{T}\right.$ cells $\mathrm{d} 0: 8.83 \pm 5.34$, d7: $16.24 \pm 5.69, P=.013 ; \mathrm{CD}^{+}$T cells d0: $21.71 \pm 14.35, \mathrm{~d} 7$ : $33.57 \pm 23.71, P=.043)$. All other surface markers remained unchanged over time ( $\mathrm{d} 4, \mathrm{~d} 7$; data not shown).

\section{Monocyte Phenotype and Subsets}

Activation markers CD69, CD40, CD80, CD86, TLR2 and HLADR on monocytes were elevated in COV compared to $\mathrm{HC}$, with significant differences for CD86 and TLR2 (Table 2). In COV, the proportion of classical monocytes $\left(\mathrm{CD} 14^{++} \mathrm{CD} 16^{-}\right)$was

TABLE 1 | Characterization of COVID-19 patients and healthy controls.

\begin{tabular}{|c|c|c|c|}
\hline Characteristic & cov & $\mathrm{HC}$ & $P$ value \\
\hline Age (years) & $64(57-72)$ & $56(47.5-63)$ & $.062^{\mathrm{a}}$ \\
\hline Male sex (\%) & $8(72.7)$ & $7(77.8)$ & $1.0^{\mathrm{C}}$ \\
\hline BMI $\left(\mathrm{kg} / \mathrm{m}^{2}\right)$ & $27.7(25.1-31.1)$ & $26.0(23.9-29.9)$ & $209^{b}$ \\
\hline \multicolumn{4}{|l|}{$\mathrm{PaO}_{2} / \mathrm{FiO}_{2}$ ratio } \\
\hline day 0 & $107(91-174)$ & & \\
\hline day 4 & $182(138-190)$ & & \\
\hline day 7 & 199 (181-234) & & \\
\hline \multicolumn{4}{|l|}{ Days } \\
\hline ventilated & $15(11.5-22.5)$ & & \\
\hline on ICU & $23(14.5-28)$ & & \\
\hline in hospital & $34(25.5-47)$ & & \\
\hline \multicolumn{4}{|l|}{ Mortality, n (\%) } \\
\hline on ICU & $0(0)$ & & \\
\hline at day 28 & $0(0)$ & & \\
\hline Leukocytes (cells/ $\mu$ l) & $10,600(7,530-12,400)$ & $5,550(4,360-6,065)$ & $.005^{\mathrm{a}}$ \\
\hline Lymphocytes (\%) & $11(9-16)$ & $28(25-40)$ & $<.001^{a}$ \\
\hline Lymphocytes (cells/ $\mu \mathrm{l})$ & $1,090(764-1,316)$ & $1,550(1,185-2,180)$ & $.033^{\mathrm{a}}$ \\
\hline Monocytes (\%) & $4(3-7)$ & $7(6-9)$ & $.038^{a}$ \\
\hline Monocytes (cells/ $\mu \mathrm{l})$ & $322(202-628)$ & $360(320-465)$ & $.732^{\mathrm{a}}$ \\
\hline Neutrophils (\%) & 74 (64-82) & $62(49-66)$ & $.018^{a}$ \\
\hline Neutrophils (cells/pl) & $7,530(6,230-9,980)$ & $2,980(2,090-3,775)$ & $.010^{\mathrm{a}}$ \\
\hline Thrombocytes $\left(\times 10^{9} / \mathrm{L}\right)$ & $336(241-387)$ & $211(172-258)$ & $.006^{\mathrm{b}}$ \\
\hline Erythrocytes (×10 $12 / L)$ & $4.01(3.17-4.22)$ & $4.93(4.77-5.16)$ & $<.001^{b}$ \\
\hline Hemoglobin (g/dl) & 11.5 (9.8-12.3) & 15 (14.5-15.6) & $<.001^{\mathrm{b}}$ \\
\hline
\end{tabular}

Values are given as median (IQR). Differences between COV and HC were calculated using two-tailed unpaired Student's $t$ test $\left.{ }^{\circ}\right)$, Mann Whitney $U$ Test $\left({ }^{\circ}\right)$ or Fisher's Exact test $(\%)$. COV, COVID-19, $n=11 ; \mathrm{HC}$, healthy controls, $n=9$; ICU, intensive care unit.

Significant differences are indicated in bold font. 
A

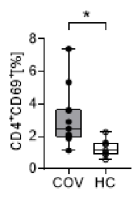

B

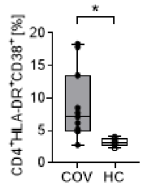

C
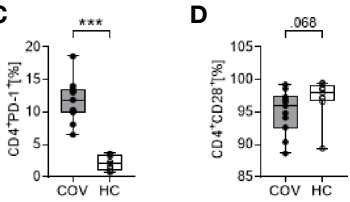

$\mathbf{E}$
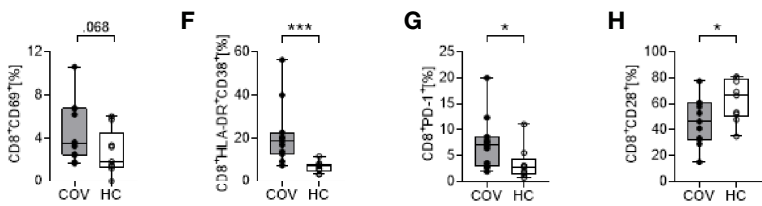

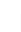
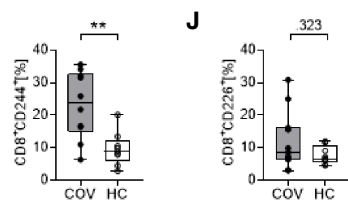

cytokine concentrations of IL-10 were found elevated in COV, and IFN $\gamma$ and IL-18 tended to be higher than in HC while IL-2, IL- $1 \alpha$ and IL-1 $\beta$ did not differ (Figure 3C).

\section{Ex Vivo Immune Response in a Second Hit Model}

Bacteria and fungi can cause secondary infections and worsen the patient's prognosis $(20,23)$. Thus, we aimed to assess the immune response against the Gram-negative bacterial component LPS, the Gram-positive bacteria L. monocytogenes and the fungi C. albicans and A. fumigatus by ex vivo incubation of whole blood with the respective antigens to mimic microbial superinfection in critically ill COVID-19 patients. After stimulation, changes in cytokine release and leukocyte phenotype in COV and $\mathrm{HC}$ were determined.

\section{Cytokine Pattern After Antigen Stimulation}

Cytokine patterns in basal control samples were similar to those of native blood, with elevated cytokine levels in COV, compared to HC. Stimulation with LPS, HKLM and A. fumigatus induced comparable increases in concentrations of IL- 6 , TNF, IL- $1 \alpha$, IL$1 \beta$, IL- 8 and IL-10 in COV and HC, while an IFN $\gamma$ response was only observed in HC, and IL-2, sIL2R $\alpha$, and IL- 18 were unaffected in both groups, compared to basal controls (Figure 4 and Table 3). Similarly, C. albicans induced an increase of IL-6, TNF, IL-1 $\alpha$, IL- $1 \beta$, IFN $\gamma$, IL-10 and IL-8 in HC; however, the release of IL-6, TNF, IL- $1 \alpha$, IL-1 $\beta$, IL-10, and IFN $\gamma$ was abrogated in COV, with no statistical difference of IL-10, IL-6, TNF, IL-1 $\beta$, and IFN $\gamma$ compared to basal controls (Figure 4 and Table 3 ).

\section{T Cell and Monocyte Phenotype After Antigen Stimulation}

Since COV showed a weakened cytokine response to C. albicans but not to LPS, HKLM, or A. fumigatus, we exemplarily compared $\mathrm{T}$ cell and monocyte phenotypes of $C$. albicans and HKLM stimulated samples of COV and HC.

In T cells, $\mathrm{COV}$ and $\mathrm{HC}$ displayed a similar expression pattern of CD69, HLA-DR/CD38, PD-1, CD28, CD244, and CD226 on both $\mathrm{CD}^{+}$and $\mathrm{CD}^{+} \mathrm{T}$ cells after C. albicans or HKLM stimulation compared to basal control (Supplementary Table 1).

Similarly, COV monocyte subsets of classical, intermediate, and non-classical monocytes showed no differences after stimulation (Supplementary Figure 1), and expression of CD69, CD40, CD86, TLR2, and HLA-DR did not differ between antigens or COV and HC (Supplementary Table 2). In contrast, expression of CD80 was significantly lower after $C$. albicans stimulation in COV compared to HC (Figure 5).

\section{Plasma Cytokine Pattern}

Upon ICU admission, concentrations of IL-6, IL-8, TNF and sIL2R $\alpha$ (Figure 3A) were significantly increased, indicating monocyte activation syndrome in these patients. Over time, levels of IL-6, IL-8, TNF and sIL2R $\alpha$ decreased from $\mathrm{d} 0$ to $\mathrm{d} 4$ and remained low on $\mathrm{d} 7$ (Figure 3B). Additionally, plasma

TABLE 2 | Cell surface marker expression on monocytes of COVID-19 patients and healthy controls.

\begin{tabular}{|c|c|c|c|}
\hline Surface marker Monocytes & cov & $\mathrm{HC}$ & $P$ value \\
\hline $\mathrm{CD}_{14}^{+}{ }^{+} \mathrm{CD} 69^{+}$ & 4.96 (3.79- 7.05) & $1.94(1.09-5.80)$ & $.058^{\mathrm{b}}$ \\
\hline $\mathrm{CD}_{14}{ }^{+} \mathrm{CD} 40^{+}$ & $4.62(2.86-8.11)$ & $2.12(0.14-4.94)$ & $.068^{\mathrm{b}}$ \\
\hline $\mathrm{CD} 14^{+} \mathrm{CD} 80^{+}$ & $3.69(1.27-5.61)$ & $1.83(0.51-3.37)$ & $.111^{\mathrm{b}}$ \\
\hline $\mathrm{CD}_{14}{ }^{+} \mathrm{CD} 86^{+}$ & $46.43(28.93-68.46)$ & 21.86 (9.73-35.83) & $.014^{\mathrm{a}}$ \\
\hline CD14 $^{+}$TLR2 $^{+}$ & 97.92 (95.82-99.06) & 91.44 (88.99-93.46) & $<.001^{\mathrm{a}}$ \\
\hline CD14 $^{+}{ }^{H}$ A-DR ${ }^{+}$ & $71.24(64.45-92.18)$ & 75.07 (55.25-85.44) & $.440^{a}$ \\
\hline
\end{tabular}

Values are given as median (IQR) and represent percentages of surface marker positive cells of total monocytes. COV, COVID-19 ( $n=11)$; HC, healthy controls ( $n=9)$. Differences between COV and HC were calculated using two-tailed unpaired Student's t test ${ }^{\beta}$ ) or Mann-Whitney U Test $\left.{ }^{\rho}\right)$.

Significant differences are indicated in bold font. 


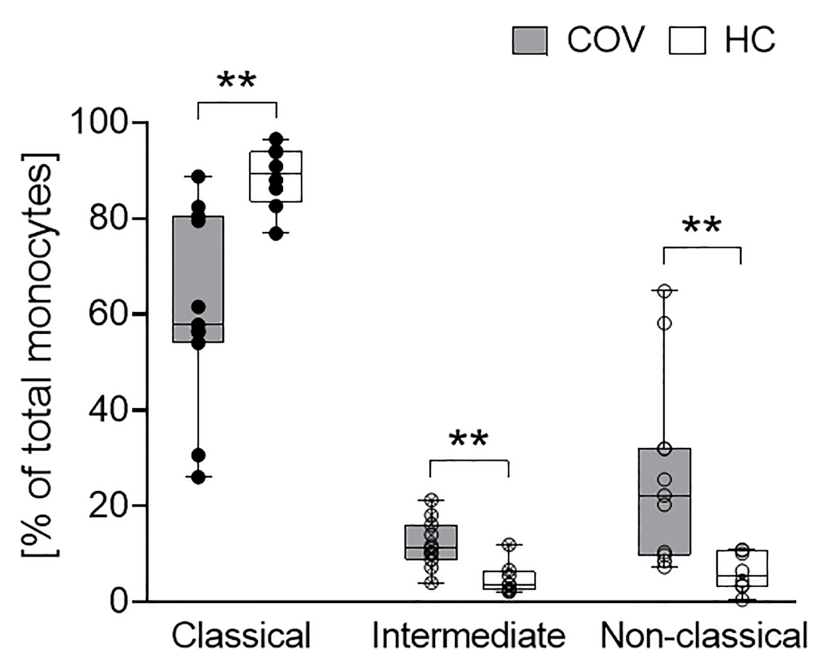

FIGURE 2 | Classical (CD14 ${ }^{++} \mathrm{CD} 16^{-}$, left), intermediate (CD14 ${ }^{++} \mathrm{CD} 16^{+}$, middle) and non-classical (CD14 ${ }^{+} \mathrm{CD} 16^{++}$, right) monocyte subsets in COVID19 patients (COV, $n=11$, gray boxes) and healthy controls $(\mathrm{HC}, \mathrm{n}=9$, white boxes). Values represent percentages of total monocytes. Boxes indicate median and interquartile range; whiskers represent minimum and maximum, dots represent single values. COV samples were compared to $\mathrm{HC}$ samples using unpaired two-tailed $t$ test or Mann-Whitney $U$ test, ${ }^{\star \star} P<.01$.

Taken together, critically ill COVID-19 patients and healthy controls did not substantially differ in their phenotype and cytokine response to LPS, HKLM and A. fumigatus, but a lower expression of CD80 on monocytes and an abrogated release of IL-10, IL-6, TNF, IL-1 $\alpha$, and IL-1 $\beta$ indicates an impaired response to $C$. albicans.

\section{DISCUSSION}

In the present study, we provide detailed analyses of the immune state of critically ill COVID-19 patients during their ICU stay and compare them to healthy controls. In COV, low lymphocyte counts are combined with pronounced $\mathrm{T}$ cell activation with elevated expression of CD69, HLA-DR/CD38 and PD-1, while monocytes display highly proinflammatory properties. An ex vivo whole blood assay reveals a similar immune response of COV and HC to LPS, HKLM and A. fumigatus, but an impaired response of $\mathrm{COV}$ toward $C$. albicans.

\section{T Cell and Monocyte Phenotypes and Plasma Cytokines in Severe COVID-19}

Both $\mathrm{CD}^{+}$and $\mathrm{CD}^{+} \mathrm{T}$ cells in $\mathrm{COV}$ showed an increased surface expression of CD69 and co-expression of HLA-DR and CD38, a constellation which has been characterized as $\mathrm{T}$ cell hyperactivity (24-26). T cell hyperactivation in COVID-19 is in accordance with findings from other groups (24, 27). High proportions of $\mathrm{CD} 226^{+}$and $\mathrm{CD} 244^{+} \mathrm{CD} 8^{+} \mathrm{T}$ cells correspond to a described virus-specificity with increased cytotoxic effector function (28-31). By exhibiting high proliferative and cytotoxic effector functions (25), these cells contribute to viral control (32). Concomitantly, $\mathrm{T}$ cells expressed high levels of $\mathrm{PD}-1$, which is involved in $\mathrm{T}$ cell inhibition (33). Elevated PD-1 expression on
$\mathrm{CD}^{+}$and $\mathrm{CD} 8^{+} \mathrm{T}$ cells is found on activated $\mathrm{T}$ cells and has been recognized as an indicator for cell exhaustion during chronic human viral infections $(34,35)$ and in COVID-19 $(24,36,37)$.

Persistent viral antigen exposure during chronic viral infections such as HIV was found to induce a terminal differentiation into effector type over memory type $\mathrm{CD}^{+} \mathrm{T}$ cells, which ultimately experience immune exhaustion and succumb to AICD before pathogen eradication (25). The pathomechanism of SARS-CoV-2 infection differs from chronic HIV or HCV infection, however, given the reduced proportion of central memory $\mathrm{CD}^{+} \mathrm{T}$ cells in $\mathrm{COV}$, it may be speculated that prolonged SARS-CoV-2 exposure leads to excessive $\mathrm{T}$ cell activation, where terminal differentiation into effector cells predominates memory cell development. This can be followed by cell exhaustion and AICD, resulting in lymphopenia and thus, may be relevant for the outcome of COVID-19 (38).

Monocytes of COV displayed in parts an enhanced expression of activation markers, indicating an increased potential to activate the adaptive immune response. Unaffected expression of HLA-DR in COV is in contrast to previous reports of downregulated HLADR in COVID-19 (39-41). However, the immune response of COVID-19 patients with ARDS can be categorized into three different groups: i) immune dysregulation with low HLA-DR expression and features of sepsis-induced immune paralysis, ii) monocyte activation syndrome with high inflammatory responses, mildly affected HLA-DR levels and sustained immune response and iii) an intermediate functional state, lacking these immune dysregulations (40). Here, the observed mildly affected monocyte HLA-DR expression, the clear increase of plasma cytokines and the pronounced immune response toward LPS, HKLM and A. fumigatus in stimulation assays infers monocyte activation syndrome rather than immune paralysis $(40,42)$. Accordingly, monocyte subsets in COV show a high non-classical proportion, confirming previous reports (41). Except for changes in HLA$\mathrm{DR}^{+} \mathrm{CD} 38^{+}$co-expression on $\mathrm{T}$ cells, there were no further alterations in surface marker expression neither on $\mathrm{T}$ cells nor on monocytes over time, indicating persistence of SARS-CoV-2induced immunological alterations.

Cytokine release patterns further confirmed monocyte activation syndrome in COV $(40,42)$. IL-6 and IL-8 plasma concentration declined on $\mathrm{d} 4$ and $\mathrm{d} 7$, which may in parts be caused by the antiinflammatory properties of hydroxychloroquine and azithromycin, which both possess IL-6 lowering activity $(43,44)$. Similarly and in accordance with previous reports $(42,45)$, the median IL-18 concentration was increased in $\mathrm{COV}$, without statistical significance. In contrast, IL- $1 \beta$ remained low, suggesting disturbances in inflammasome activation during COVID-19.

\section{Ex Vivo Immune Stimulation Assays Uncover Deficiency Toward C. albicans in COVID-19}

Fungal superinfections have been observed in COVID-19, with COVID-19-associated candidiasis representing one major complication (12, 15, 46-48). The involvement of immune dysfunction in Candida spp. superinfections during COVID-19 is not yet understood (15). Thus, leukocyte phenotypes and cytokine responses were investigated by whole blood ex vivo incubation 


\section{IL-6 $\quad$ TNF $\quad$ IL-8 $\quad$ sIL-2R $\alpha$}

A
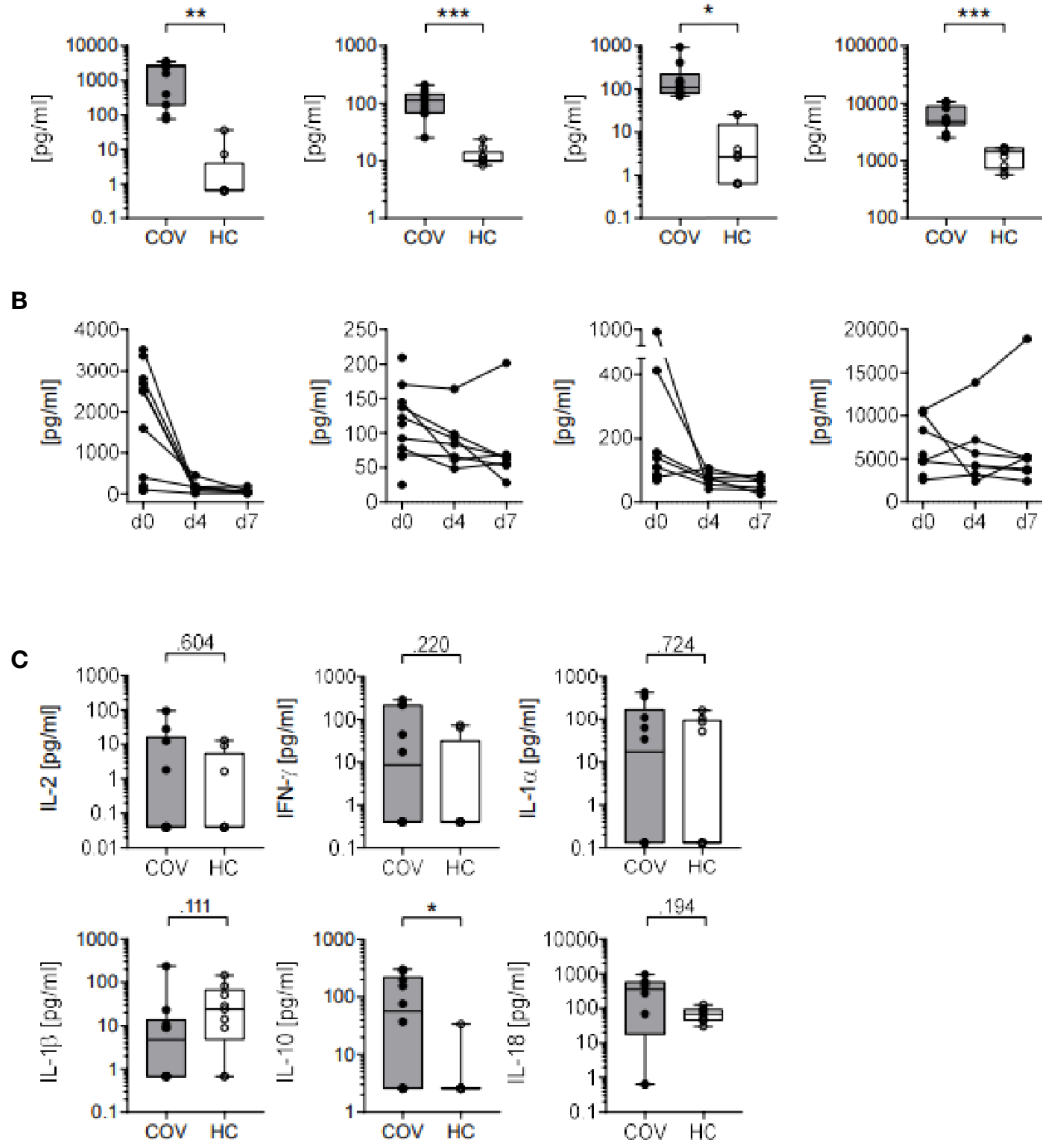

FIGURE 3 | Plasma cytokine concentrations in COVID-19 patients (COV, $n=10$, gray box) and healthy controls (HC, $n=9$, white box). (A) IL-6, TNF, IL-8 and sIL2R $\alpha$ cytokine concentrations ( $\mathrm{pg} / \mathrm{ml})$ on day 0 and $(\mathbf{B})$ on days $(\mathrm{d}) \mathrm{0}, 4(\mathrm{n}=7)$, and $7(\mathrm{n}=7)$ in COV. (C) Concentrations of IL-2, IFN $\gamma$, IL-1 $\alpha$, IL-1 $\beta$, IL-10, and $\mathrm{IL}-18$ on day 0 (COV, $n=8-11)$ and healthy controls $(\mathrm{HC}, \mathrm{n}=9$, white box). Boxes indicate median and interquartile range, whiskers represent minimum and maximum, dots represent single values. Statistical differences between COV and HC were calculated using unpaired two-tailed $t$ test or Mann-Whitney $U$ test, ${ }^{\star} P<.05 ;{ }^{\star \star} P<.01 ;{ }^{* \star *} P<.001$

assays with LPS, HKLM, A. fumigatus, and C. albicans. The commensal polymorphic fungus C. albicans represents a member of the human microbiome and does not harm the host in an immunocompetent state. During immune system disturbances however, it can cause infections of superficial skin and mucous membranes up to life-threatening systemic infections (12, 49-51).

In $\mathrm{T}$ cells and monocytes, activation capacities as well as costimulatory and antigen-presenting properties in monocytes were maintained, and in contrast to HC, stimulation did not influence monocyte subtype proportions in COV. However, monocyte surface expression of co-stimulatory $\mathrm{CD} 80$ in response to $C$. albicans was significantly less increased compared to HC, indicating attenuated monocyte activation by this fungus and as a consequence, reduced co-stimulatory effects of CD80 on the adaptive immune response. This conclusion is supported by the impaired cytokine release profile. Here, concentrations of nearly all tested monocyte activation syndrome relevant cytokines were unaffected by C. albicans stimulation, whereas LPS-, HKLM- and A. fumigatus-induced cytokine secretion was similar to HC. The lacking immune response toward C. albicans antigen but not toward HKLM, which can both act as TLR2 agonists $(21,52,53)$, or toward LPS or A. fumigatus adds to the notion of preserved immune function in $\mathrm{COV}$, and is inconsistent with results indicating a generally attenuated TLR response of the peripheral innate immune system from COVID-19 patients (54).

An adequate immune response against $C$. albicans is elicited after sensing of fungal cell wall components such as $\beta$-glucans and $\alpha$-mannans by distinct surface pattern recognition receptors on monocytes and macrophages. These include in particular C-type lectin receptors (e.g., Dectin-1, Dectin 2/3, Mincle), NOD-like receptors and TLR2/4 (55-57). Activation of these receptors induces activation of downstream Syk and NF- $\mathrm{KB}$ signaling, resulting in NLRP3 inflammasome activation and production of pro-inflammatory cytokines such as TNF, IL-1 $\beta$ and IL-18, which 


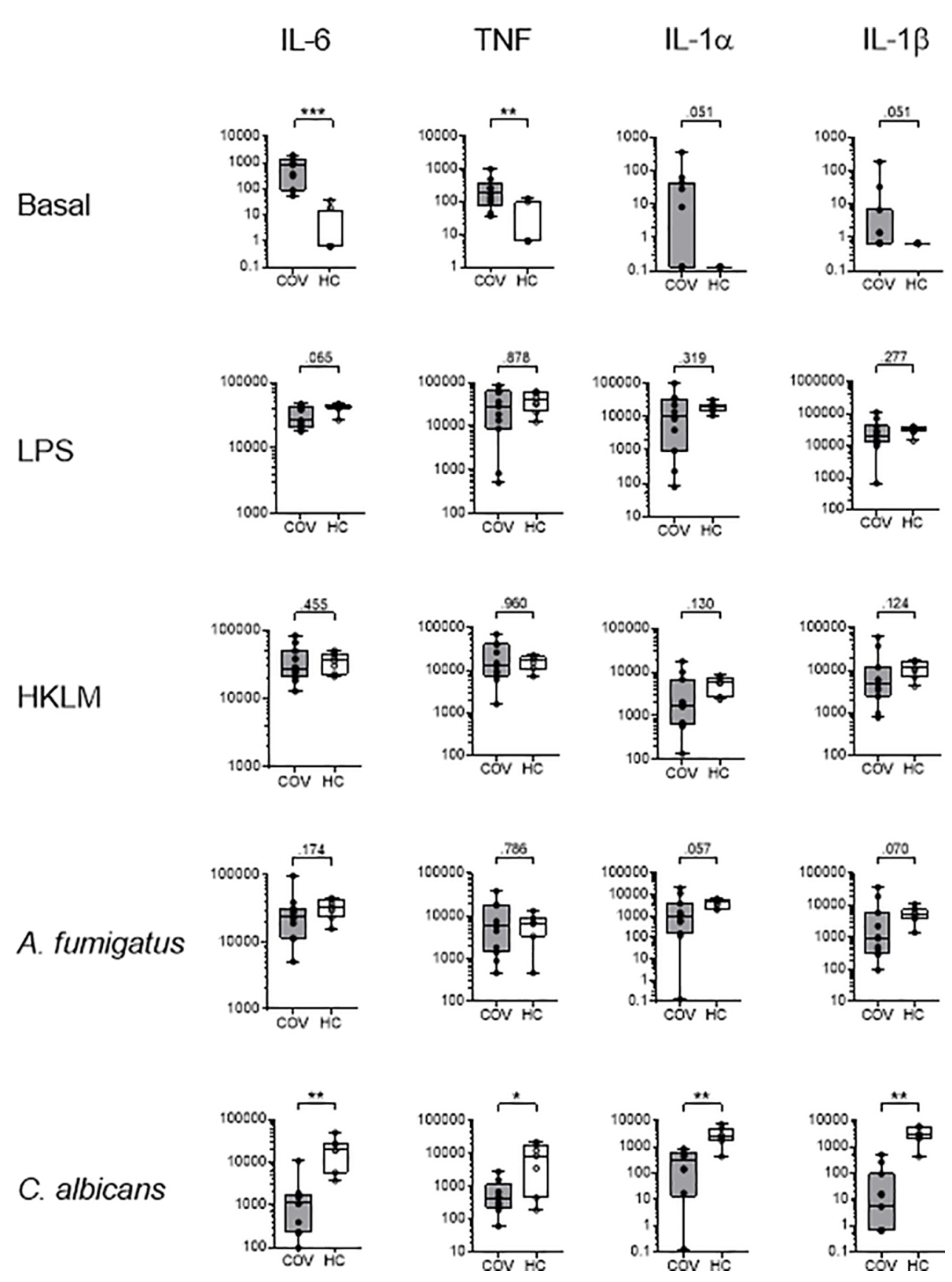

FIGURE 4 | Cytokine concentrations (pg/ml) of IL-6, TNF, IL-1 $\alpha$ and IL-1 $\beta$ in supernatants of whole blood samples from COVID-19 patients (COV, $\mathrm{n}=11$, gray box) and healthy controls $(\mathrm{HC}, \mathrm{n}=7-9$, white box) after ex vivo antigen incubation (basal, LPS, HKLM, A. fumigatus, C. albicans). Boxes indicate median and interquartile range, whiskers represent minimum and maximum, dots represent single values. Statistical differences were calculated using unpaired two-tailed $t$ test or Mann Whitney $U$ test, ${ }^{\star} P<.05,{ }^{\star \star} P<.01,{ }^{\star \star \star} P<.001$.

mediate fungicidal activity $(55,57,58)$. Although we observed enhanced IL-18 concentrations in COV, a SARS-CoV-2-induced activation of NLRP3 as described by others $(59,60)$ is in discordance with low IL-1 $\beta$ levels and the lack of IL- $1 \beta$ increase after stimulation with $C$. albicans. To elucidate the exact mechanism of the disturbed immune response to C. albicans on the monocyte level, further investigations are needed, such as functional analyses of relevant surface receptors like Dectin-1 and -2 (57) and the associated Syk signaling pathway (61) as well as the pyroptotic signaling pathway, containing NLRP3 inflammasome and caspase- 1 activation and IL- $1 \beta$ secretion (58).

Limitations of this work include the small sample size, which can only partially be compensated for by analyses of multiple time points. Due to a lack of patients with pneumonia caused by other viruses than SARS-CoV-2, healthy volunteers were used as controls for our comparative analyses.

Despite these limitations, our results provide first evidence of a disturbed immune response toward $C$. albicans, which may 
TABLE 3 | Cytokine concentrations in supernatants of COVID-19 patients and healthy controls after ex vivo antigen incubation (basal, LPS, HKLM, A. fumigatus, C. albicans).

\begin{tabular}{|c|c|c|c|c|c|c|c|c|c|}
\hline \multirow[t]{2}{*}{ Cytokine (pg/ml) } & \multicolumn{3}{|c|}{ Basal } & \multicolumn{3}{|c|}{ LPS } & \multicolumn{3}{|c|}{ HKLM } \\
\hline & cov & $\mathrm{HC}$ & $P$ & cov & $\mathrm{HC}$ & $P$ & cov & $\mathrm{HC}$ & $P$ \\
\hline IL-2 & $\begin{array}{c}0.04 \\
(0.04-0.70)\end{array}$ & $<$ LOD & $.112^{b}$ & $\begin{array}{c}0.04 \\
(0.04-0.70)\end{array}$ & $<\mathrm{LOD}$ & $.112^{\mathrm{b}}$ & $\begin{array}{c}0.04 \\
(0.04-1.31)\end{array}$ & $<$ LOD & $.112^{b}$ \\
\hline IFN $\gamma$ & $\begin{array}{c}0.40 \\
(0.4-111.20)\end{array}$ & $<$ LOD & $.093^{b}$ & $\begin{array}{c}124.52 \\
(0.40-166.20)\end{array}$ & $\begin{array}{c}3189.40 \\
(1385.29- \\
6144.24)\end{array}$ & $<.001^{\mathrm{b}}$ & $\begin{array}{c}10.82 \\
(0.40-134.48)\end{array}$ & $\begin{array}{c}453.41 \\
(261.92-619.87)\end{array}$ & $<.001^{b}$ \\
\hline IL-10 & $\begin{array}{c}2.60 \\
(2.6-44.13)\end{array}$ & $<$ LOD & $.073^{b}$ & $\begin{array}{c}1282.71 \\
(290.88-2492.44)\end{array}$ & $\begin{array}{c}488.62 \\
(282.72-591.88)\end{array}$ & $.124^{b}$ & $\begin{array}{c}587.83 \\
(406.43-2625.29)\end{array}$ & $\begin{array}{c}635.23 \\
(438.27-35.63)\end{array}$ & $.717^{\mathrm{b}}$ \\
\hline IL-8 & $\begin{array}{c}1379.80 \\
(378.80-2719.66)\end{array}$ & $\begin{array}{c}218.18 \\
(85.07-388.38)\end{array}$ & $.011^{b}$ & $\begin{array}{c}5513.64 \\
(3257.59- \\
8002.47)\end{array}$ & $\begin{array}{c}3690.49 \\
(2237.11- \\
8048.28)\end{array}$ & $.610^{\mathrm{a}}$ & $\begin{array}{c}5144.01 \\
(2633.66- \\
8234.36)\end{array}$ & $\begin{array}{l}5495.46 \\
(2232.60- \\
12744.94)\end{array}$ & $.717^{\mathrm{b}}$ \\
\hline sIL2R $\alpha$ & $\begin{array}{c}2733.10 \\
(1877.33- \\
4326.63)\end{array}$ & $\begin{array}{c}542.45 \\
(374.07-681.67)\end{array}$ & $<.001^{b}$ & $\begin{array}{c}2938.69 \\
(1602.30-769.40)\end{array}$ & $\begin{array}{c}537.01 \\
(409.95-617.38)\end{array}$ & $<.001^{b}$ & $\begin{array}{c}3081.62 \\
(1618.11- \\
4023.78)\end{array}$ & $\begin{array}{c}565.92 \\
(379.75-604.33)\end{array}$ & $<.001^{b}$ \\
\hline IL-18 & $\begin{array}{c}224.95 \\
(32.96-476.05)\end{array}$ & $\begin{array}{c}0.64 \\
(0.64-31.99)\end{array}$ & $.006^{\mathrm{b}}$ & $\begin{array}{c}300.65 \\
(108.85-616.43)\end{array}$ & $\begin{array}{c}0.64 \\
(0.64-76.99)\end{array}$ & $.001^{b}$ & $\begin{array}{c}277.82 \\
(107.24-490.20)\end{array}$ & $\begin{array}{c}0.64 \\
(0.64-11.52)\end{array}$ & $<.001^{b}$ \\
\hline \multirow[t]{2}{*}{ Cytokine (pg/ml) } & \multicolumn{3}{|c|}{ A. fumigatus } & \multicolumn{3}{|c|}{ C. albicans } & & & \\
\hline & cov & $\mathrm{HC}$ & $P$ & cov & $\mathrm{HC}$ & $P$ & & & \\
\hline IL-2 & $\begin{array}{c}0.04 \\
(0.04-0.24)\end{array}$ & $<$ LOD & $.112^{\mathrm{b}}$ & $\begin{array}{c}0.04 \\
(0.04-4.89)\end{array}$ & $<\mathrm{LOD}$ & $.563^{\mathrm{b}}$ & & & \\
\hline IFN- & $\begin{array}{c}10.36 \\
(0.40-102.27)\end{array}$ & $\begin{array}{c}306.12 \\
(174.10-462.95)\end{array}$ & $<.001^{b}$ & $\begin{array}{c}2.59 \\
(0.40-54.88)\end{array}$ & $\begin{array}{c}206.30 \\
(43.28-418.47)\end{array}$ & $.022^{\mathrm{b}}$ & & & \\
\hline IL-10 & $\begin{array}{c}246.74 \\
(132.65-952.70)\end{array}$ & $\begin{array}{c}196.50 \\
(162.39-466.64)\end{array}$ & $.526^{\mathrm{b}}$ & $\begin{array}{c}2.60 \\
(2.60-44.92)\end{array}$ & $\begin{array}{c}292.05 \\
(166.25-408.86)\end{array}$ & $.002^{\mathrm{b}}$ & & & \\
\hline IL-8 & $\begin{array}{c}3520.71 \\
(1909.91- \\
7727.71)\end{array}$ & $\begin{array}{c}3032.29 \\
(1399.32- \\
6602.88)\end{array}$ & $.415^{b}$ & $\begin{array}{c}2745.24 \\
(2252.91- \\
4110.54)\end{array}$ & $\begin{array}{c}2290.30 \\
(1990.57- \\
4721.37)\end{array}$ & $.464^{b}$ & & & \\
\hline sIL2R $\alpha$ & $\begin{array}{c}3017.12 \\
(1762.30- \\
3859.42)\end{array}$ & $\begin{array}{c}549.70 \\
(362.38-628.19)\end{array}$ & $<.001^{b}$ & $\begin{array}{c}3091.67 \\
(1905.49- \\
4110.20)\end{array}$ & $\begin{array}{c}529.74 \\
(414.47-615.01)\end{array}$ & $<.001^{b}$ & & & \\
\hline IL-18 & $\begin{array}{c}233.42 \\
(140.17-442.54)\end{array}$ & $\begin{array}{c}0.64 \\
(0.64-0.64)\end{array}$ & $<.001^{b}$ & $\begin{array}{c}139.78 \\
(18.82-443.98)\end{array}$ & $\begin{array}{c}0.64 \\
(0.64-11.11)\end{array}$ & $.004^{b}$ & & & \\
\hline
\end{tabular}

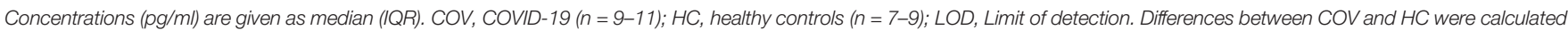
using unpaired Student's t test $\left.{ }^{(}\right)$or Mann-Whitney $U$ test $\left.{ }^{\circ}\right)$.

Significant differences are indicated in bold font.

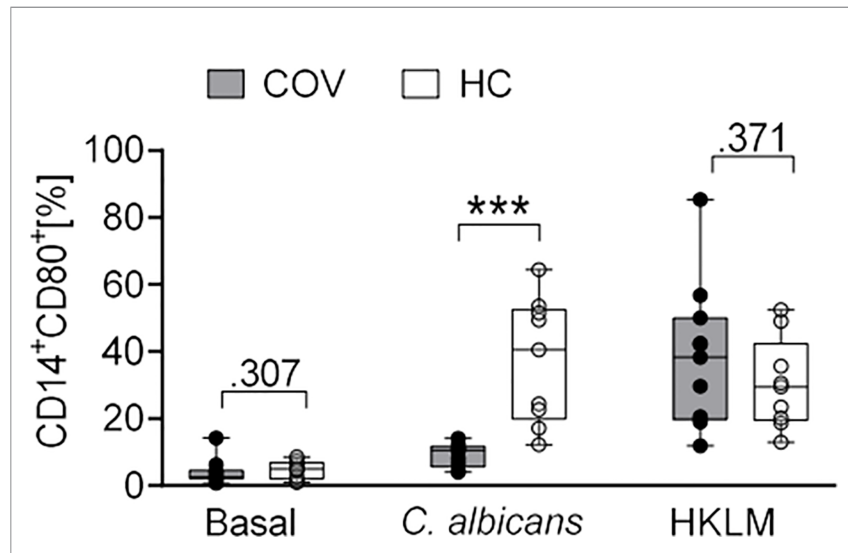

FIGURE 5 | CD80 expression on monocytes after ex vivo antigen incubation (basal, C. albicans, HKLM) in COVID-19 patients (COV, $n=11$, gray box) and healthy controls ( $\mathrm{HC}, \mathrm{n}=9$, white box). Values represent percentages of surface marker positive cells of total CD14 ${ }^{+}$cells. Boxes indicate median and interquartile range; whiskers represent minimum and maximum, dots represent single values. Differences between groups were calculated using unpaired two-tailed $t$ test or Mann-Whitney $U$ test, ${ }^{\star \star \star} P<.001$. hint at an increased susceptibility toward infection with C. albicans in critically ill COVID-19 patients. We consider the immune response characterization of critical COVID-19 cases as relevant for the field, and the blunted cytokine response to stimulation with $C$. albicans noteworthy to both immunologists and clinicians.

\section{DATA AVAILABILITY STATEMENT}

The raw data supporting the conclusions of this article will be made available by the authors, without undue reservation.

\section{ETHICS STATEMENT}

The studies involving human participants were reviewed and approved by the Ludwig-Maximilians University Medical Faculty Ethics Committee. The patients/participants or next of kins/carers provided their written informed consent to participate in this study. 


\section{AUTHOR CONTRIBUTIONS}

$\mathrm{DM}, \mathrm{AC}$, and TW designed the study. $\mathrm{DM}, \mathrm{KB}, \mathrm{BH}, \mathrm{MH}$, and TW performed experiments and collected data, and data analysis was performed by DM and TW. The article was drafted by DM, AC, and TW, and critical revision for important intellectual content was performed by all authors (DM, KB, BH, MH, GS, AC, and TW). All authors contributed to the article and approved the submitted version.

\section{FUNDING}

This work was supported by the German Aerospace Center (DLR) and the Federal Ministry of Economic Affairs and Technology [50WB1931, RP1920].

\section{REFERENCES}

1. Huang C, Wang Y, Li X, Ren L, Zhao J, Hu Y, et al. Clinical features of patients infected with 2019 novel coronavirus in Wuhan, China. Lancet (London England) (2020) 395:497-506. doi: 10.1016/s0140-6736(20)30183-5

2. Zhou P, Yang XL, Wang XG, Hu B, Zhang L, Zhang W, et al. A pneumonia outbreak associated with a new coronavirus of probable bat origin. Nature (2020) 579:270-3. doi: 10.1038/s41586-020-2012-7

3. Gao YM, Xu G, Wang B, Liu BC. Cytokine storm syndrome in coronavirus disease 2019: A narrative review. J Internal Med (2020) 289(2):147-61. doi: 10.1111/joim.13144

4. Abers MS, Delmonte OM, Ricotta EE, Fintzi J, Fink D, de Jesus AA, et al. An immune-based biomarker signature is associated with mortality in COVID19 patients. JCI Insight (2020) 6(14):e144455. doi: 10.1172/jci.insight. 144455

5. Remy KE, Mazer M, Striker DA, Ellebedy AH, Walton AH, Unsinger J, et al. Severe immunosuppression and not a cytokine storm characterizes COVID19 infections. JCI Insight (2020) 5:1-15. doi: 10.1172/jci.insight.140329

6. Garcia-Vidal C, Sanjuan G, Moreno-García E, Puerta-Alcalde P, GarciaPouton N, Chumbita M, et al. Incidence of co-infections and superinfections in hospitalized patients with COVID-19: a retrospective cohort study. Clin Microbiol Infect Off Publ Eur Soc Clin Microbiol Infect Dis (2020) 27(1):83-8. doi: 10.1016/j.cmi.2020.07.041

7. Arastehfar A, Carvalho A, van de Veerdonk FL, Jenks JD, Koehler P, Krause R, et al. COVID-19 Associated Pulmonary Aspergillosis (CAPA)-From Immunology to Treatment. J Fungi (Basel Switzerland) (2020). doi: 10.3390/ jof6020091

8. White PL, Dhillon R, Cordey A, Hughes H, Faggian F, Soni S, et al. A national strategy to diagnose COVID-19 associated invasive fungal disease in the ICU. Clin Infect Dis Off Publ Infect Dis Soc America (2020). doi: 10.1093/cid/ciaa1298

9. Al-Hatmi AMS, Mohsin J, Al-Huraizi A, Khamis F. COVID-19 associated invasive candidiasis. J Infect (2020) S0163-4453(20)30539-9. doi: 10.1016/ j.jinf.2020.08.005

10. Antinori S, Bonazzetti C, Gubertini G, Capetti A, Pagani C, Morena V, et al. Tocilizumab for cytokine storm syndrome in COVID-19 pneumonia: an increased risk for candidemia? Autoimmun Rev (2020) 19:102564. doi: 10.1016/j.autrev.2020.102564

11. Chowdhary A, Tarai B, Singh A, Sharma A. Multidrug-Resistant Candida auris Infections in Critically Ill Coronavirus Disease Patients, India, April-July 2020. Emerg Infect Dis (2020) 26:2694-6. doi: 10.3201/eid2611.203504

12. Mastrangelo A, Germinario BN, Ferrante M, Frangi C, Li Voti R, Muccini C, et al. Candidemia in COVID-19 patients: incidence and characteristics in a prospective cohort compared to historical non-COVID-19 controls. Clin Infect Dis Off Publ Infect Dis Soc America (2020), ciaa1594. doi: 10.1093/ cid/ciaa1594

13. White PL, Dhillon R, Healy B, Wise MP, Backs M. Candidaemia in COVID19 , a link to disease pathology or increased clinical pressures? Clin Infect Dis Off Publ Infect Dis Soc America (2020) ciaa1597. doi: 10.1093/cid/ciaa1597

\section{ACKNOWLEDGMENTS}

The authors thank Dr. Judith-Irina Buchheim and Prof. Matthias Feuerecker for valuable discussion, Matthias Witte, Elisa Aue, and Florian Brandes for their support with sample collection, the ICU team under the lead of PD. Dr. Michael Irlbeck, and all participants of this study.

\section{SUPPLEMENTARY MATERIAL}

The Supplementary Material for this article can be found online at: https://www.frontiersin.org/articles/10.3389/fimmu.2021.640644/ full\#supplementary-material

14. Heard KL, Hughes S, Mughal N, Moore LSP. COVID-19 and fungal superinfection. Lancet Microbe (2020) 1:e107. doi: 10.1016/S2666-5247(20) 30065-3

15. Arastehfar A, Carvalho A, Nguyen MH, Hedayati MT, Netea MG, Perlin DS, et al. COVID-19-Associated Candidiasis (CAC): An Underestimated Complication in the Absence of Immunological Predispositions? J Fungi (Basel Switzerland) (2020) 6(4):211. doi: 10.3390/jof6040211

16. Cunha C, Carvalho A, Esposito A, Bistoni F, Romani L. DAMP signaling in fungal infections and diseases. Front Immunol (2012) 3:286:286. doi: 10.3389/ fimmu.2012.00286

17. Hoenigl M. Invasive Fungal Disease complicating COVID-19: when it rains it pours. Clin Infect Dis Off Publ Infect Dis Soc America (2020) ciaa1342. doi: $10.1093 / \mathrm{cid} /$ ciaa1342

18. Tolle LB, Standiford TJ. Danger-associated molecular patterns (DAMPs) in acute lung injury. J Pathol (2013) 229:145-56. doi: 10.1002/path.4124

19. Kullberg BJ, Arendrup MC. Invasive Candidiasis. New Engl J Med (2015) 373:1445-56. doi: 10.1056/NEJMra1315399

20. Marra AR, Camargo LF, Pignatari AC, Sukiennik T, Behar PR, Medeiros EA, et al. Nosocomial bloodstream infections in Brazilian hospitals: analysis of 2,563 cases from a prospective nationwide surveillance study. J Clin Microbiol (2011) 49:1866-71. doi: 10.1128/jcm.00376-11

21. Woehrle T, Du W, Goetz A, Hsu HY, Joos TO, Weiss M, et al. Pathogen specific cytokine release reveals an effect of TLR2 Arg753Gln during Candida sepsis in humans. Cytokine (2008) 41:322-9. doi: 10.1016/j.cyto.2007.12.006

22. World Medical Association World Medical Association Declaration of Helsinki: ethical principles for medical research involving human subjects. Jama (2013) 310:2191-4. doi: 10.1001/jama.2013.281053

23. Morgan MP, Szakmany T, Power SG, Olaniyi P, Hall JE, Rowan K, et al. Sepsis Patients with First and Second-Hit Infections Show Different Outcomes Depending on the Causative Organism. Front Microbiol (2016) 7:207:207. doi: 10.3389/fmicb.2016.00207

24. De Biasi S, Meschiari M, Gibellini L, Bellinazzi C, Borella R, Fidanza L, et al. Marked T cell activation, senescence, exhaustion and skewing towards TH17 in patients with COVID-19 pneumonia. Nat Commun (2020) 11:3434. doi: 10.1038/s41467-020-17292-4

25. Gonzalez SM, Taborda NA, Rugeles MT. Role of Different Subpopulations of CD8(+) T Cells during HIV Exposure and Infection. Front Immunol (2017) 8:936:936. doi: 10.3389/fimmu.2017.00936

26. Meditz AL, Haas MK, Folkvord JM, Melander K, Young R, McCarter M, et al. HLA-DR+ CD38+ CD4+ T lymphocytes have elevated CCR5 expression and produce the majority of R5-tropic HIV-1 RNA in vivo. J Virol (2011) 85:10189-200. doi: 10.1128/jvi.02529-10

27. Xu Z, Shi L, Wang Y, Zhang J, Huang L, Zhang C, et al. Pathological findings of COVID-19 associated with acute respiratory distress syndrome. Lancet Respir Med (2020) 8:420-2. doi: 10.1016/s2213-2600(20)30076-x

28. Huang Z, Qi G, Miller JS, Zheng SG. CD226: An Emerging Role in Immunologic Diseases. Front Cell Dev Biol (2020) 8:564:564. doi: 10.3389/fcell.2020.00564 
29. Schlaphoff V, Lunemann S, Suneetha PV, Jaroszewicz J, Grabowski J, Dietz J, et al. Dual function of the NK cell receptor 2B4 (CD244) in the regulation of HCV-specific CD8+ T cells. PloS Pathog (2011) 7:e1002045. doi: 10.1371/ journal.ppat.1002045

30. Wu Y, Anasetti C, Yu XZ. T-Cell Costimulation and Coinhibition in GraftVersus-Host Disease and Graft-Versus-Leukemia Effect. In: RZ Gérard Socié, BR Blazar, editors. Immune Biology of Allogeneic Hematopoietic Stem Cell Transplantation, 2nd ed. Academic Press (2019). p. 167-94.

31. Agresta L, Hoebe KHN, Janssen EM. The Emerging Role of CD244 Signaling in Immune Cells of the Tumor Microenvironment. Front Immunol (2018) 9:2809:2809. doi: 10.3389/fimmu.2018.02809

32. Ndhlovu ZM, Kamya P, Mewalal N, Kløverpris HN, Nkosi T, Pretorius K, et al. Magnitude and Kinetics of CD8+ T Cell Activation during Hyperacute HIV Infection Impact Viral Set Point. Immunity (2015) 43:591-604. doi: 10.1016/j.immuni.2015.08.012

33. Zhu X, Lang J. Soluble PD-1 and PD-L1: predictive and prognostic significance in cancer. Oncotarget (2017) 8:97671-82. doi: 10.18632/ oncotarget.18311

34. Barber DL, Wherry EJ, Masopust D, Zhu B, Allison JP, Sharpe AH, et al. Restoring function in exhausted CD8 $\mathrm{T}$ cells during chronic viral infection. Nature (2006) 439:682-7. doi: 10.1038/nature04444

35. Day CL, Kaufmann DE, Kiepiela P, Brown JA, Moodley ES, Reddy S, et al. PD-1 expression on HIV-specific T cells is associated with T-cell exhaustion and disease progression. Nature (2006) 443:350-4. doi: 10.1038/nature 05115

36. Diao B, Wang C, Tan Y, Chen X, Liu Y, Ning L, et al. Reduction and Functional Exhaustion of T Cells in Patients With Coronavirus Disease 2019 (COVID-19). Front Immunol (2020) 11:827:827. doi: 10.3389/fimmu.2020.00827

37. Paces J, Strizova Z, Smrz D, Cerny J. COVID-19 and the immune system. Physiol Res (2020) 69:379-88. doi: 10.33549/physiolres.934492

38. Huang I, Pranata R. Lymphopenia in severe coronavirus disease-2019 (COVID-19): systematic review and meta-analysis. J Intensive Care (2020) 8:36. doi: 10.1186/s40560-020-00453-4

39. Kox M, Frenzel T, Schouten J, van de Veerdonk FL, Koenen H, Pickkers P. COVID-19 patients exhibit less pronounced immune suppression compared with bacterial septic shock patients. Crit Care (London England) (2020) 24:263. doi: 10.1186/s13054-020-02896-5

40. Giamarellos-Bourboulis EJ, Netea MG, Rovina N, Akinosoglou K, Antoniadou A, Antonakos N, et al. Complex Immune Dysregulation in COVID-19 Patients with Severe Respiratory Failure. Cell Host Microbe (2020) 27:992-1000.e1003. doi: 10.1016/j.chom.2020.04.009

41. Pence BD. Severe COVID-19 and aging: are monocytes the key? GeroScience (2020) 42:1051-61. doi: 10.1007/s11357-020-00213-0

42. Merad M, Martin JC. Pathological inflammation in patients with COVID-19: a key role for monocytes and macrophages. Nat Rev Immunol (2020) 20:35562. doi: 10.1038/s41577-020-0331-4

43. Patel A, Joseph J, Periasamy H, Mokale S. Azithromycin in Combination with Ceftriaxone Reduces Systemic Inflammation and Provides Survival Benefit in a Murine Model of Polymicrobial Sepsis. Antimicrobial Agents Chemother (2018) 62:1-13. doi: 10.1128/aac.00752-18

44. Wu R, Wang L, Kuo HD, Shannar A, Peter R, Chou PJ, et al. An Update on Current Therapeutic Drugs Treating COVID-19. Curr Pharmacol Rep (2020), 1-15. doi: 10.1007/s40495-020-00216-7

45. Chen G, Wu D, Guo W, Cao Y, Huang D, Wang H, et al. Clinical and immunological features of severe and moderate coronavirus disease 2019. J Clin Invest (2020) 130:2620-9. doi: 10.1172/jci137244

46. Lai CC, Wang CY, Hsueh PR. Co-infections among patients with COVID-19: The need for combination therapy with non-anti-SARS-CoV-2 agents?
J Microbiol Immunol Infect Wei Mian Yu Gan Ran Za Zhi (2020) 53:50512. doi: $10.1016 /$ j.jmii.2020.05.013

47. Salehi M, Ahmadikia K, Mahmoudi S, Kalantari S, Jamalimoghadamsiahkali S, Izadi A, et al. Oropharyngeal candidiasis in hospitalised COVID-19 patients from Iran: Species identification and antifungal susceptibility pattern. Mycoses (2020) 63:771-8. doi: 10.1111/myc.13137

48. Song G, Liang G, Liu W. Fungal Co-infections Associated with Global COVID-19 Pandemic: A Clinical and Diagnostic Perspective from China. Mycopathologia (2020) 185:599-606. doi: 10.1007/s11046-020-00462-9

49. Gozalbo D, Maneu V, Gil ML. Role of IFN-gamma in immune responses to Candida albicans infections. Front Biosci (Landmark Ed) (2014) 19:1279-90. doi: $10.2741 / 4281$

50. Mayer FL, Wilson D, Hube B. Candida albicans pathogenicity mechanisms. Virulence (2013) 4:119-28. doi: 10.4161/viru.22913

51. Zuo T, Zhan H, Zhang F, Liu Q, Tso EYK, Lui GCY, et al. Alterations in Fecal Fungal Microbiome of Patients With COVID-19 During Time of Hospitalization until Discharge. Gastroenterology (2020) 159:13021310.e1305. doi: 10.1053/j.gastro.2020.06.048

52. Gil ML, Gozalbo D. Role of Toll-like receptors in systemic Candida albicans infections. Front Biosci (Landmark Ed) (2009) 14:570-82. doi: 10.2741/3263

53. Torres D, Barrier M, Bihl F, Quesniaux VJ, Maillet I, Akira S, et al. Toll-like receptor 2 is required for optimal control of Listeria monocytogenes infection. Infect Immun (2004) 72:2131-9. doi: 10.1128/iai.72.4.2131-2139.2004

54. Arunachalam PS, Wimmers F, Mok CKP, Perera R, Scott M, Hagan T, et al. Systems biological assessment of immunity to mild versus severe COVID-19 infection in humans. Science (2020) 369:1210-20. doi: 10.1126/ science.abc6261

55. Tang J, Lin G, Langdon WY, Tao L, Zhang J. Regulation of C-Type Lectin Receptor-Mediated Antifungal Immunity. Front Immunol (2018) 9:123:123. doi: 10.3389/fimmu.2018.00123

56. Wang W, Deng Z, Wu H, Zhao Q, Li T, Zhu W, et al. A small secreted protein triggers a TLR2/4-dependent inflammatory response during invasive Candida albicans infection. Nat Commun (2019) 10:1015. doi: 10.1038/s41467-01908950-3

57. Heung LJ. Monocytes and the Host Response to Fungal Pathogens. Front Cell Infect Microbiol (2020) 10:34:34. doi: 10.3389/fcimb.2020.00034

58. Wellington M, Koselny K, Sutterwala FS, Krysan DJ. Candida albicans triggers NLRP3-mediated pyroptosis in macrophages. Eukaryotic Cell (2014) 13:32940. doi: 10.1128/ec.00336-13

59. Freeman TL, Swartz TH. Targeting the NLRP3 Inflammasome in Severe COVID-19. Front Immunol (2020) 11:1518:1518. doi: 10.3389/fimmu.2020.01518

60. van den Berg DF, Te Velde AA. Severe COVID-19: NLRP3 Inflammasome Dysregulated. Front Immunol (2020) 11:1580. doi: 10.3389/fimmu.2020.01580

61. Uwamahoro N, Verma-Gaur J, Shen HH, Qu Y, Lewis R, Lu J, et al. The pathogen Candida albicans hijacks pyroptosis for escape from macrophages. mBio (2014) 5:e00003-00014. doi: 10.1128/mBio.00003-14

Conflict of Interest: The authors declare that the research was conducted in the absence of any commercial or financial relationships that could be construed as a potential conflict of interest.

Copyright () 2021 Moser, Biere, Han, Hoerl, Schelling, Choukér and Woehrle. This is an open-access article distributed under the terms of the Creative Commons Attribution License (CC BY). The use, distribution or reproduction in other forums is permitted, provided the original author(s) and the copyright owner(s) are credited and that the original publication in this journal is cited, in accordance with accepted academic practice. No use, distribution or reproduction is permitted which does not comply with these terms. 